\title{
Dual infective burden of Helicobacter pylori and intestinal parasites: Good or bad news for the host?
}

\author{
Zahid Hussain $^{1} \cdot$ Emad El-Omar $^{2} \cdot$ Yeong Yeh Lee ${ }^{2,3}$ \\ Published online: 5 May 2020 \\ (C) Indian Society of Gastroenterology 2020
}

Gastric cancer (GC) remains an important public health concern worldwide, and the best-known carcinogen is Helicobacter pylori (H. pylori), a Gram-negative helical shaped bacterium found in the stomach by Marshall and Warren $[1,2]$. Although $H$. pylori infects nearly half of the world population including India [3] and Malaysia [4], GC rates vary in different populations [5]. Despite the high prevalence of $H$. pylori, India reported low rates of $\mathrm{GC}$ (the Indian Enigma) similar to the Zulia population reported in study by Fuenmayor-Boscán et al. [6, 7]. However, the Chinese in Malaysia have the highest reported rates of $H$. pylori and also GC among the three ethnic groups (the cohort effect) [8]. A similarity between India and Zulia is the high burden of unicellular parasites and multicellular worms typically found in these communities [6, 7]. From the above observations thus arise the following questions:

'Why does H. pylori follow a benign course in certain individuals but malignant in others?'

'Could the intestinal parasites co-infection with H. pylori explain the enigma?'

Yeong Yeh Lee

justnleeyy@gmail.com

1 Department of Internal Medicine, Gangnam Severance Hospital, Yonsei University College of Medicine, Seoul, South Korea

2 Microbiome Research Centre, St George and Sutherland Clinical School, University of New South Wales, Sydney, Australia

3 School of Medical Sciences, Universiti Sains Malaysia, Kota Bharu, Malaysia

\section{The bad news - overdrive effects of Th1 responses}

H. pylori-infected hosts have been shown to display strong polarization of T helper 1 (Th1) cells [9]. The dominance of Th1 over Th2 responses promotes the secretion of proinflammatory cytokines including IL-2, IL-12, IL-18, TNF- $\alpha$ and INF- $\gamma$ (Fig. 1) $[10,11]$. However, the presence of intestinal protozoa (rather than helminth) together with $H$. pylori has been shown to exaggerate (rather than attenuate) the host immune responses [9]. Coinfection of parasites and H. pylori actually supplements the recruitment of Th1 cells, aggravates the responses against both microbial entities and intensifies gastric mucosal damage [9].

Another important player is the Th17 cells, which upon activation by $H$. pylori infection, release the cytokines including IL-17A, IL-17F, IL-21 and IL-22 [9-11] (Fig. 1). These intermediaries are involved in antimicrobial activity directed against extracellular bacteria and fungi [10, 12, 13]. Th17mediated secretion of cytokines affects the production of the proinflammatory cytokine IL- 8 and activates the intercellular adhesion molecules-1 (ICAM-1) [14]. The Th17 mediated events then stimulate the chemotaxis of neutrophils into the gastric tissue [14]. Neutrophil infiltration has damaging effects on the gastric mucosa due to reactive forms of oxygen and nitrogen generated by these white cells [11]. Mediators such as histamine and protease (tryptase) are also released by activated mast cells Th17 response, which then induce vasodilation and edema [11].

So, both the Th1 and Th17 responses are activated by the host to clear H. pylori (and protozoa or parasites) but often unexpectedly these responses may fail to eradicate $H$. pylori from the gastrointestinal (GI) tract. The reason for failure of clearance is unclear but mucosal recruitment of regulatory $\mathrm{T}$ lymphocytes (Treg) may be important. It has been shown that the over-activated Tregs in gastric mucosa could diminish the 


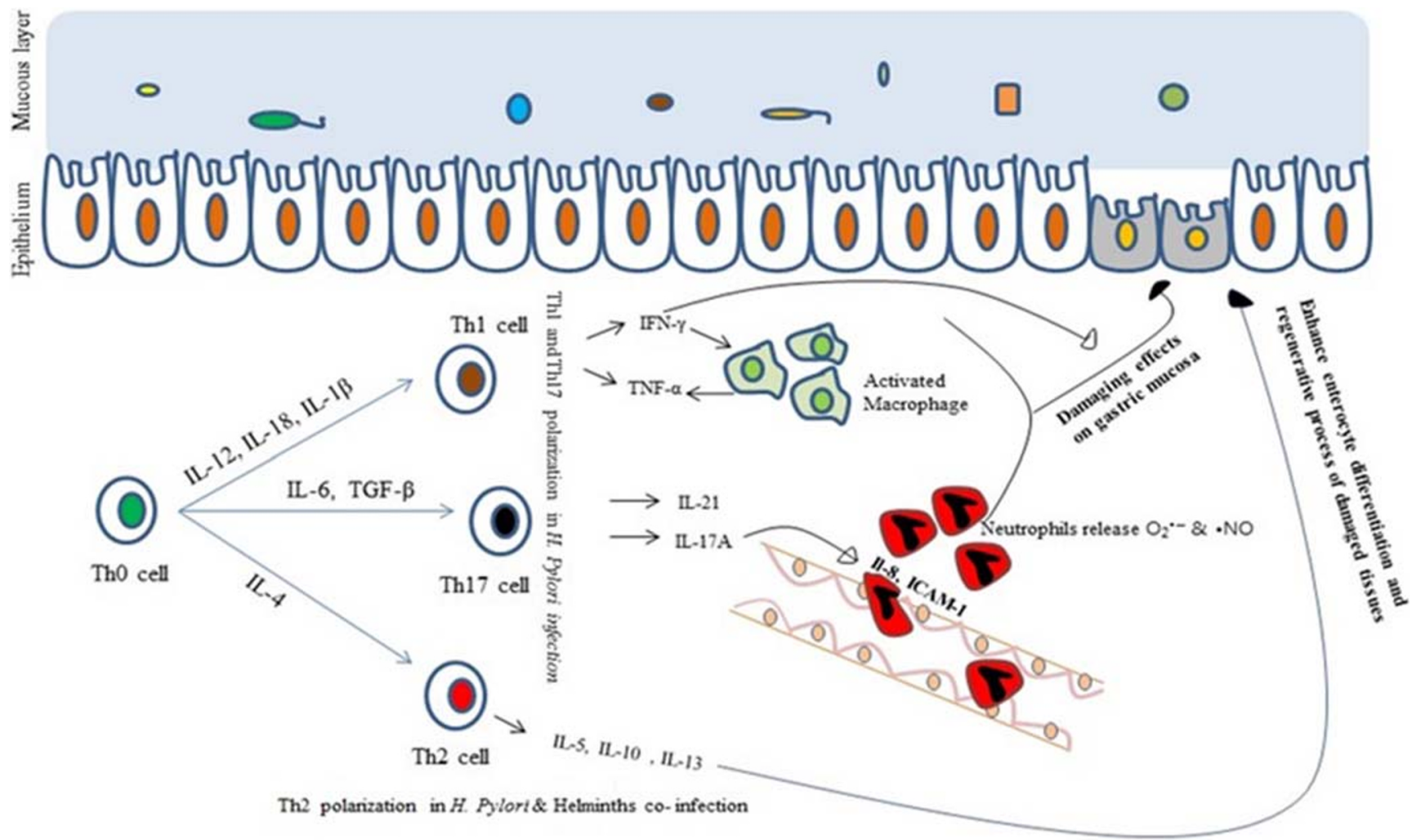

Th2 suppress proinflammatory immune response

Fig. 1 The role of immunological cells in Helicobacter pylori (H. pylori) and helminths coinfection. H. pylori infection polarize T helper 1 (Th1), it stimulates the secretion of proinflammatory cytokines Interleukin-12 (IL12), IL-18, IL-1 $\beta$, Tumor necrosis factor- $\alpha$ (TNF- $\alpha)$ and Interferon- $\gamma$ $(\mathrm{INF}-\gamma)$. INF- $\gamma$ in turn activates macrophages, release TNF- $\alpha$. H pylori infection also activates Th17 and releases cytokines 1L-17A, IL-17F, IL-21 and IL-22. These cytokines affect the production of proinflammatory cytokine IL-
8 and activates intercellular adhesion molecules-1 (ICAM-1) and stimulates chemotaxis of neutrophils. The combined effects of TNF- $\alpha$, INF- $\gamma$ and reactive species released by neutrophils damage gastric mucosa. H. pylori coinfection with helminths on the other hand polarize Th2 cells via IL-4 and secrete IL-4, IL-10 and IL-13 which suppress proinflammatory immune response of Th1 and Th17 and hence enhance enterocyte differentiation and regenerative process of damaged tissues antibacterial host immune reaction towards $H$. pylori and initiate gastric mucosal damage [10]. The hygiene theory may be the basis for the over-activated Treg response observed in the stomach $[15,16]$, where early exposure to a diverse range of microbes including $H$. pylori might have activated protective immune processes that also include Treg cells [17]. In addition, the host's genetic polymorphism of different pro-inflammatory, anti-inflammatory, xenobiotic metabolizing enzyme and adhesion molecule gene polymorphisms might have influenced the outcome of $H$. pylori infection $[18,19]$.

\section{The good news - enhanced Th2 responses with Helminth co-infection}

Unlike protozoa, helminths are multicellular and capable of surviving in the host for decades, often with little damaging effects unless there is a high worm burden [20]. Also, unlike protozoa and $H$. pylori, helminths drive predominantly Th2 responses, and probably due to this reason, a host that is infected by trichuris species is somewhat protected from inflammatory bowel disease $[20,21]$. Activation of Th2 cells release cytokines including IL-4, IL-5, IL-10 and IL-13, and these cytokines suppress the proinflammatory immune response and enhance the regenerative processes of damaged tissues $[9,22]$. Activation of Th2 is also favorable to the recruitment of eosinophils in the stomach, since eosinophils store many compounds that are involved in tissue repair and remodeling [23]. As a result, population with significant exposure to helminthic infection also have lower prevalence of allergic diseases $[18,19]$.

It is hypothesized that coinfection with intestinal helminths (rather than protozoa or parasites) may induce protective effects against $H$. pylori through alleviation of Th1 dependent responses and thus inflammation in the stomach [9, 24]. These findings have been demonstrated in animal models but not in humans. However, the recent study of Fuenmayor-Boscán et al. in Zulia state of Venezuela has replicated findings of animal models in humans [7]. Although, limited in sample size, they clearly showed overexpression of proinflammatory 
cytokines (IL- $1 \beta$, TNF- $\alpha$ and IFN- $\gamma$ ), in addition to higher IFN- $\gamma /$ IL- 4 ratio in the $H$. pylori infected individuals as compared to H. pylori negative control group [7]. On the other hand, individuals with helminth infection exhibited decrease in the expression of proinflammatory cytokines and increase in the degree of expression of the cytokine IL-4 and lower IFN- $\gamma /$ IL-4 ratio [7].

\section{The good news - beneficial effects on the gut barrier from Helminth co-infection}

The epithelial lining of the gut is the interface but also the barrier between the body proper (i.e. lamina propria and mucosa) and the gut lumen [25]. An essential function of the barrier is to prevent harmful elements (antigens or microbes including protozoa and helminths) in the lumen from gaining access below the mucosa and to the circulatory system. The main components of gut barrier include the thick mucus produced from goblet cells, trefoil factors, defensins or the other antimicrobial peptides from the Paneth cells, serotonin from the enterochromaffin (EC) cells, and secretory IgA [26]. Several studies have indicated that $H$. pylori was not only able to colonize the human gastric epithelium but have also evolved numerous strategies to perturb the integrity of the gastric barrier allowing its continued survival [27, 28].

On the other hand, helminth-induced changes on the epithelium may potentially compromise the survival strategy of H. pylori. These helminth-evoked changes have included enhanced epithelial cell turnover and goblet cell hyperplasia; both phenomena assist in expulsion of intestinal helminths [29-32] but also likely H. pylori. Helminths also induce Paneth cell hyperplasia, and therefore regulate the release of antimicrobial peptides $[33,34]$ although more work is required to identify which of these peptides are harmful to H. pylori. Helminths infection may also have effect on GI motility mediated through the enteric nervous system by serotonin, a critical signaling molecule involved in a wide range of physiological functions such as secretion, sensing and signaling $[35,36]$. ECs within the enteric epithelium are the body's major source of serotonin [36]. However, there have been contradictory findings in which one study demonstrates an increase [37] while another showed a decrease [36] in intestinal ECs and serotonin levels with helminthic infection.

H. pylori are normally found adhering to gastric epithelial cells near the apical junctional complex [38], and apart from gastric surface, the bacterium has been identified within the lamina propria, gastric lymph nodes and within the intracellular canaliculi of parietal cells (Fig. 2) [39]. Disruption of the tight junction complex is assisted by genes related to $H$. pylori $[37,38]$. In contrast, intestinal helminths are too big to reside within an epithelial cell, but helminths do cause increases in gut permeability by 'scratching' the epithelium directly or from helminth-derived products [9]. For example, infection with nematodes has been found to increase epithelial permeability by compromising the paracellular spaces and tight junctions [40]. Furthermore, helminth infection promotes mast cell hyperplasia and activation, and the release of proteases from mast cells can affect tight junction proteins and gut permeability [41]. Helminths are also adept at manipulating the host immunity to serve their own needs; for example, it results in the release of alarmins from enterocytes which then promote Th2 type immunity $[42,43]$.

\section{The controversy - role of Helminth co-infection on the gut microbiome}

The gut microbiome plays a central homeostatic role in health and disease but this homeostasis may be disrupted by different intrinsic and extrinsic factors [44]. While the evidence is clear that $H$. pylori can disrupt the gut microbiome [45, 46], the same cannot be said about helminths in which the literature is sparse and at times contradictory [47]. A few animal studies evaluated the relationship between helminth infection with alterations of gut microbiota composition $[48,49]$ and there are reports of adverse changes. For example, Su et al. reported that coinfection with the intestinal helminth heligmosomoides polygyrus (H. polygyrus) exacerbated intestinal inflammation caused by the bacterial pathogen Citrobacter rodentium due to increase in abundance of Bacteroidetes and reductions in Firmicutes and Lactobacillales [50]. The effects of the helminth-altered microbiota appear to be detrimental based on the study by $\mathrm{Su}$ et al, presumably because the helminths interfere with immune responses that are required for Citrobacter clearance [50].

However, a few studies have shown beneficial effects of helminths on the gut microbiome [51-53]. For example, Lee et al. compared fecal samples of helminth-infected vs. noninfected individuals residing in rural Malaysia and reported a significant increase in bacterial diversity among individuals infected with any helminth species [51]. Similarly, Cantacessi et al. reported increased bacterial richness among patients with celiac disease infected with helminths [52]. In another study, Whary et al. reported that helminth infection may provide protection against $H$. pylori-induced gastric adenocarcinoma [53]. Helminth infection may also have prevented increased bacterial colonization of the stomach and therefore reduced number of neoplastic lesions [29]. However, the mechanism by which helminths alter the gut microbiome diversity is still not clear. Intact Th2 response and activation or polarization of regulatory T-cells may play a central role in helminth-induced variations in the gut microbiota $[42,50,54]$. Alternatively, helminth-induced effects on the gut microbiome may occur independent of the Th2 immune response [55]. 


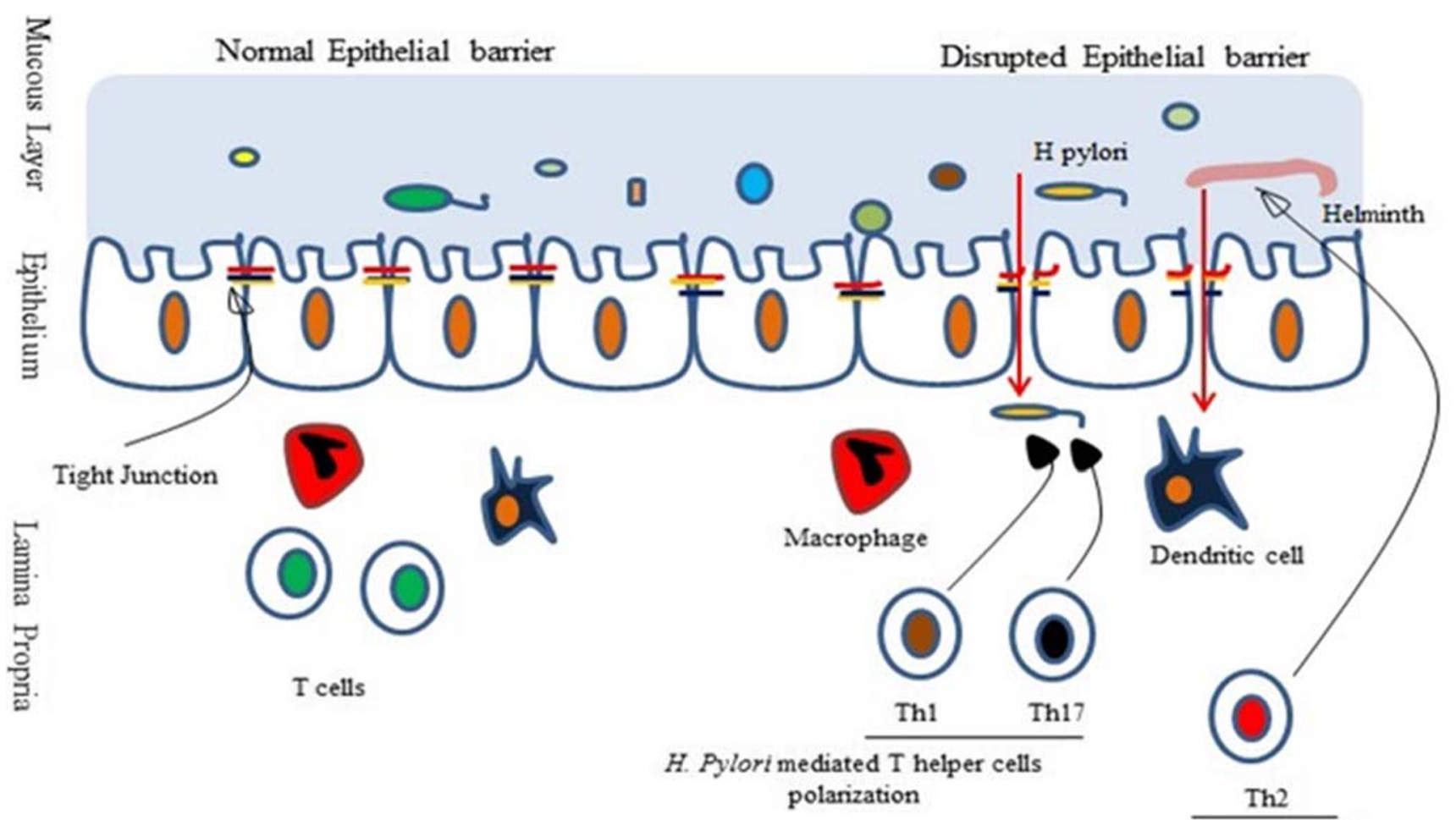

Helminth mediated T helper cells polarization

Fig. 2 Helicobacter pylori (H. pylori) mediated disruption of epithelial barrier integrity. H. pylori adhere to gastric epithelial cells near apical junctional complex. H pylori genes disrupt the tight junction complex. $H$. pylori infections polarize Th1 and stimulate the secretion of proinflammatory cytokines and damages gastric mucosa. Helminths coinfection polarizes Th2 polarization and suppresses the damaging effects of Th1 and Th17. The mechanism how intestinal helminths would reverse the disruption of epithelial barrier integrity induced by $H$. pylori and prevents the colonization of pathogenic microbes is still unanswered
There are a number of environmental and lifestyle factors associated with gastric carcinogenesis and H. pylori (Table 1), one of which is dietary factor. Earlier studies showed that some foods were protective against carcinogenesis (e.g. onion, curcumin, fruits, vegetables etc.) whereas others promoted it (meat, fish, excess salt etc.) [56]. Diet may also have a direct influence on the pathogenesis and rates of $H$. pylori infection; for example, centenella asiatica and budu (fish sauce) have been found to be associated with a lower prevalence of H. pylori among the Malays [57]. Diet is known to modulate the gut microbiota [58]; for example, vegetarians reported significant variations in their gut microbiota from the nonvegetarians [59]. Likewise food preservatives alter microbiota $[60,61]$. It is probable that gastric carcinogenesis associated with diet may be mediated by gut dysbiosis [62-66].
Table 1 Environmental and lifestyle factors altering the risk of gastric cancer associated with Helicobacter pylori [56]

\begin{tabular}{ll}
\hline Factors associated with gastric cancer & Protective factors against gastric cancer \\
\hline Genetic factors & Total vegetables, onion, garlic \\
Processed meat & Selenium \\
Artificial preservatives & Vitamin C \\
Smoking and other environmental factors & Zinc element in drinking water \\
Dysbiosis & Vitamin E, Carotenoid $(\alpha$ and $\beta)$ \\
Geographical factors & Coffee and black tea \\
& Green tea
\end{tabular}




\section{Summary and future direction}

Interactions between $H$. pylori, parasites, and the host are under the influence of multiple factors including immune responses, gut barrier function and gut microbiome and hence subject to variable clinical consequences including development of GC. Indeed, H. pylori infection has been shown to have detrimental effects on the host gastric mucosa. Coinfection with protozoa may worsen gastric pathology but co-infection with helminths may be potentially beneficial, with gastric outcomes largely mediated by the balance between Th1 and Th2 responses. Epithelial barrier integrity, gut microbiota, diet and host genetic factors may have pivotal roles in determining the ultimate clinical outcomes of coinfection with parasites but at the present time, research is limited and sometimes contradictory.

\section{Compliance with ethical standards}

Conflict of interest ZH, EE-O and YYL declare that they have no conflicts of interest.

Disclaimer The authors are solely responsible for the data and the content of the paper. In no way, the Honorary Editor-in-Chief, Editorial Board Members, or the printer/publishers are responsible for the results/ findings and content of this article.

\section{References}

1. Marshall BJ, Warren JR. Unidentified curved bacilli on gastric epithelium in active chronic gastritis. Lancet. 1983;321:1273-5.

2. Marshall BJ, Warren JR. Unidentified curved bacilli in the stomach of patients with gastritis and peptic ulceration. Lancet. 1984;323: 1311-5.

3. Ghoshal UC, Tripathi S, Ghoshal U. The Indian enigma of frequent $\mathrm{H}$. pylori infection but infrequent gastric cancer: is the magic key in Indian diet, host's genetic make up, or friendly bug? Am J Gastroenterol. 2007;102:2113-4.

4. Lee YY, Mahendra Raj S, Graham DY. Helicobacter pylori infection-a boon or a bane: lessons from studies in a lowprevalence population. Helicobacter. 2013;18:338-46.

5. World Gastroenterology Organization Global Guideline. Helicobacter pylori in developing countries. J Dig Dis. 2011;12: 319-26.

6. Ghoshal UC, Chaturvedi R, Correa P. The enigma of Helicobacter pylori infection and gastric cancer. Indian J Gastroenterol. 2010;29: 95-100.

7. Fuenmayor-Boscán A, Hernández-Rincón I, Arismendi-Morillo G, et al. Changes in the severity of gastric mucosal inflammation associated to Helicobacter pylori in humans coinfected by intestinal helminths. Indian J Gastroenterol. 2020;39: DOI https://doi.org/10. 1007/s12664-020-01023-0.

8. Goh KL, Cheah PL, Md N, et al. Ethnicity and H. Pylori as risk factors for gastric cancer in Malaysia: a prospective case control study. Am J Gastroenterol. 2007;102:40-5.

9. Krzyżek P, Gościniak G. Frequency and immunological consequences of Helicobacter pylori and intestinal parasite co-infections: a brief review. Ann Parasitol. 2017;63:255-63.
10. Larussa T, Leone I, Suraci E, et al. Helicobacter pylori and T helper cells: mechanisms of immune escape and tolerance. J Immunol Research. 2015;2015:1-10.

11. Ieni A, Barresi V, Rigoli L, et al. Morphological and cellular features of innate immune reaction in Helicobacter pylori gastritis: a brief review. Int J Mol Sci. 2016;17:109.

12. Khamri W, Walker MM, Clark P, et al. Helicobacter pylori stimulates dendritic cells to induce interleukin-17 expression from CD4+ T lymphocytes. Infect Immun. 2010;78:845-53.

13. D'Elios MM, Manghetti M, De Carli M, et al. T helper 1 effector cells specific for Helicobacter pylori in the gastric antrum of patients with peptic ulcer disease. J Immunol. 1997;158:962-7.

14. Luzza F, Parrello T, Monteleone G, et al. Up-regulation of IL-17 is associated with bioactive IL-8 expression in Helicobacter pyloriinfected human gastric mucosa. J Immunol. 2000;165:5332-7.

15. Scudellari M. News feature: cleaning up the hygiene hypothesis. Proc Natl Acad Sci US A. 2017;114:1433-6.

16. Rook GAW, Martinelli R, Brunet LR. Innate immune responses to mycobacteria and the downregulation of atopic responses. Curr Opin Allergy Clin Immunol. 2003;3:337-42.

17. Matricardi PM, Bonini S. High microbial turnover rate preventing atopy: a solution to inconsistencies impinging on the hygiene hypothesis? Clin Exp Allergy. 2000;30:1506-10.

18. Tripathi S, Ghoshal U, Mittal B, et al. Association between gastric mucosal glutathione-S-transferase activity, glutathione-Stransferase gene polymorphisms and helicobacter pylori infection in gastric cancer. Indian J Gastroenterol. 2011;30:257-63.

19. Ghoshal U, Kumar S, Jaiswal V, et al. Association of microsomal epoxide hydrolase exon 3 Tyr113His and exon 4 His139Arg polymorphisms with gastric cancer in India. Indian J Gastroenterol. 2013;32:246-52.

20. Bethony J, Brooker S, Albonico M, et al. Soil transmitted helminth infections: Ascariasis, trichuriasis, and hookworm. Lancet. 2006;367:1521-32.

21. Whary MT, Muthupalani S, Ge Z, et al. Helminth co-infection in Helicobacter pylori infected INS-GAS mice attenuates gastric premalignant lesions of epithelial dysplasia and glandular atrophy and preserves colonization resistance of the stomach to lower bowel microbiota. Microbes Infect. 2014;16:345-55.

22. Allen JE, Wynn TA. Evolution of Th2 immunity: a rapid repair response to tissue destructive pathogens. PLoS Pathog. 2011;7: e1002003.

23. Rosenberg HF, Dyer KD, Foster PS. Eosinophils: changing perspectives in health and disease. Nat Rev Immunol. 2013;13:9-22.

24. Chen F, Liu Z, Wu W, et al. An essential role for Th2-type responses in limiting acute tissue damage during experimental helminth infection. Nat Med. 2012;18:260-6.

25. Turner JR. Intestinal mucosal barrier function in health and disease. Nat Rev Immunol. 2009;9:799-809.

26. McKay DM, Shute A, Lopes F. Helminths and Intestinal barrier function. Tissue Barriers. 2017;5:e1283385.

27. Wroblewski LE, Peek RM Jr. Targeted disruption of the epithelialbarrier by Helicobacter pylori. Cell Commun Signal. 2011;9:29.

28. Alzahrani S, Lina TT, Gonzalez J, et al. Effect of Helicobacter pylori on gastric epithelial cells. World J Gastroenterol. 2014;20: 12767-80.

29. Cortes A, Munoz-Antoli C, Martin-Grau C, et al. Differential alterations in the small intestine epithelial cell turnover during acute and chronic infection with Echinostoma caproni (Trematoda). Parasites Vectors. 2015;8:334.

30. Cliffe LJ, Humphreys NE, Lane TE, et al. Accelerated intestinal epithelial cell turnover: a new mechanism of parasite expulsion. Science. 2005;308:1463-5.

31. Mullaly SC, Oudhoff MJ, Min PH, et al. Requirement for core $2 \mathrm{O}$ glycans for optimal resistance to helminth infection. PLoS One. 2013;8:e60124. 
32. Hasnain SZ, Evans CM, Roy M, et al. Muc5ac: a critical component mediating the rejection of enteric nematodes. J Exp Med. 2011;208:893-900.

33. Kamal M, Dehlawi MS, Brunet LR, Wakelin D. Paneth and intermediate cell hyperplasia induced in mice by helminth infections. Parasitology. 2002;125:275-81.

34. Hasnain SZ, McGuckin MA, Grencis RK, Thornton DJ. Serine protease(s) secreted by the nematode Trichuris muris degrade the mucus barrier. PLoS Negl Trop Dis. 2012;6:e1856.

35. McKay DM, Fairweather I. A role for the enteric nervous system in the response to helminth infections. Parasitol Today. 1997;13:63-9.

36. Manocha M, Shajib MS, Rahman MM, et al. IL-13-mediated immunological control of enterochromaffin cell hyperplasia and serotonin production in the gut. Mucosal Immunol. 2013;6:146-55.

37. Murray M, Smith WD, Waddell AH, Jarrett WF. Nippostrongylus brasiliensis: histamine and 5-hydroxytryptamine inhibition and worm expulsion. Exp Parasitol. 1971;30:58-63.

38. Amieva MR, Vogelmann R, Covacci A, et al. Disruption of the epithelial apical-junctional complex by helicobacter pylori CagA. Science. 2003;300:1430-4.

39. Ito T, Kobayashi D, Uchida K, et al. Helicobacter pylori invades the gastric mucosa and translocates to the gastric lymph nodes. Lab Investig. 2008;88:664-81.

40. Fernandez-Blanco JA, Estevez J, Shea-Donohue T, et al. Changes in epithelial barrier function in response to parasitic infection: implications for IBD pathogenesis. J Crohn's Colitis. 2015;9:463-76.

41. McDermott JR, Bartram RE, Knight PA, et al. Mast cells disrupt epithelial barrier function during enteric nematode infection. Proc Natl Acad Sci U S A. 2003;100:7761-6.

42. Maizels RM, McSorley HJ. Regulation of the host immune system by helminth parasites. J Allergy Clin Immunol. 2016;138:666-75.

43. Lopes F, Reyes JL, Wang A, et al. Enteric epithelial cells support growth of Hymenolepis diminuta in vitro and trigger TH2promoting events in a species-specific manner. Internat $\mathbf{J}$ Parasitol. 2015;45:691-6.

44. Lee YY, Hassan SA, Ismail IH, et al. Gut microbiota in early life and its influence on health and disease: a position paper by the Malaysian working group on gastrointestinal health. J Paediatr Child Health. 2017;53:1152-8.

45. Lofgren JL, Whary MT, Ge Z, et al. Lack of commensal flora in Helicobacter pylori-infected INS-GAS mice reduces gastritis and delays intraepithelial neoplasia. Gastroenterology. 2011;140:210-20.

46. Peek RM, Blaser MJ. Helicobacter pylori and gastrointestinal tract adenocarcinomas. Nat Rev Cancer. 2002;2:28-37.

47. Zaiss MM, Harris NL. Interactions between the intestinal microbiome and helminth parasites. Parasite Immunol. 2016;38: 5-11.

48. $\mathrm{Li} \mathrm{RW}, \mathrm{Wu} \mathrm{S}, \mathrm{Li} \mathrm{W}$, et al. Alterations in the porcine colon microbiota induced by the gastrointestinal nematode Trichuris suis. Infect Immun. 2012;80:2150-7.

49. Walk ST, Blum AM, Ewing SA, et al. Alteration of the murine gut microbiota during infection with the parasitic helminth Heligmosomoides polygyrus. Inflamm Bowel Dis. 2010;16:1841-9.

50. Su C, Su L, Li Y, et al. Helminth-induced alterations of the gut microbiota exacerbate bacterial colitis. Mucosal Immunol. 2018;11:144-57.
51. Lee SC, Tang MS, Lim YA, et al. Helminth colonization is associated with increased diversity of the gut microbiota. PLoS Negl Trop Dis. 2014;8:e2880.

52. Cantacessi C, Giacomin P, Croese J, et al. Impact of experimental hookworm infection on the human gut microbiota. J Infect Dis. 2014;210:1431-4

53. Whary MT, Sundina N, Bravo LE, et al. Intestinal helminthiasis in Colombian children promotes a Th2 response to Helicobacter pylori: possible implications for gastric carcinogenesis. Cancer Epidemiol Biomark Prev. 2005;14:1464-9.

54. Hussaarts L, Yazdanbakhsh M, Guigas B. Priming dendritic cells for Th2 polarization: lessons learned from helminths and implications for metabolic disorders. Fron Immunol. 2014;5:499.

55. Rausch S, Held J, Fischer A, et al. Small intestinal nematode infection of mice is associated with increased enterobacterial loads alongside the intestinal tract. PLoS One. 2013;8:e74026.

56. Lee YY, Derakhshan MH. Environmental and lifestyle risk factors of gastric cancer. Arch Iran Med. 2013;16:358-65.

57. Lee YY, Ismail AW, Mustaffa N, et al. Sociocultural and dietary practices among Malay subjects in the north-eastern region of peninsular Malaysia: a region of low prevalence of helicobacter pylori infection. Helicobacter. 2012;17:54-61.

58. Khine WWT, Zhang Y, Goie GJY, et al. Gut microbiome of preadolescent children of two ethnicities residing in three distant cities. Sci Rep. 2019;9:7831.

59. Singh N, Gurav A, Sivaprakasam S, et al. Activation of Gpr109a, receptor for niacin and the commensal metabolite butyrate, suppresses colonic inflammation and carcinogenesis. Immunity. 2014;40:128-39.

60. Irwin SV, Fisher P, Graham E, et al. Sulfites inhibit the growth of four species of beneficial gut bacteria at concentrations regarded as safe for food. PLoS One. 2017;12:e0186629.

61. Raposa B, Pónusz R, Gerencsér G, et al. Food additives: sodium benzoate, potassium sorbate, azorubine, and tartrazine modify the expression of NFKB, GADD45 $\alpha$, and MAPK8 genes. Physiol Int. 2016;103:334-43.

62. Wong SH, Yu J. Gut microbiota in colorectal cancer: mechanisms of action and clinical applications. Nat Rev Gastroenterol Hepatol. 2019;16:690-704.

63. Oh TY, Yeo M, Han SU, et al. Synergism of helicobacter pylori infection and stress on the augmentation of gastric mucosal damage and its prevention with alpha-tocopherol. Free Rad Biol Med. 2005;38:1447-57.

64. Van Hecke T, Van Camp J, Smet S. Oxidation during digestion of meat: interactions with the diet and Helicobacter pylori gastritis, and implications on human health. Comp Rev Food Sci and Food Safety. 2017;16:214-33.

65. Machida-Montani A, Sasazuki S, Inoue M, et al. Association of Helicobacter pylori infection and environmental factors in noncardia gastric cancer in Japan. Gastric Cancer. 2004;7:46-53.

66. Guo Y, Zhang Y, Gerhard M, et al. Effect of Helicobacter pylori on gastrointestinal microbiota: a population-based study in Linqu, a high-risk area of gastric cancer. Gut. 2019. pii: gutjnl-2019-319696.

Publisher's note Springer Nature remains neutral with regard to jurisdictional claims in published maps and institutional affiliations. 